Invited talk for the International Conf. on Experimental Meson Spectroscopy, Philadelphia, Pa., May 1-2, 1970
UCRL-19865

Preprint

$$
\text { Conf-700525-- } 1
$$

RECEIVED BY DTIE SEP 251970

\title{
THE $A_{2}$ AND THE $2^{+}$NONET. CONSISTENCY OF DATA
}

Angela Barbaro-Galtieri

June 1970

AEC Contract No. W $-7405-$ eng -48

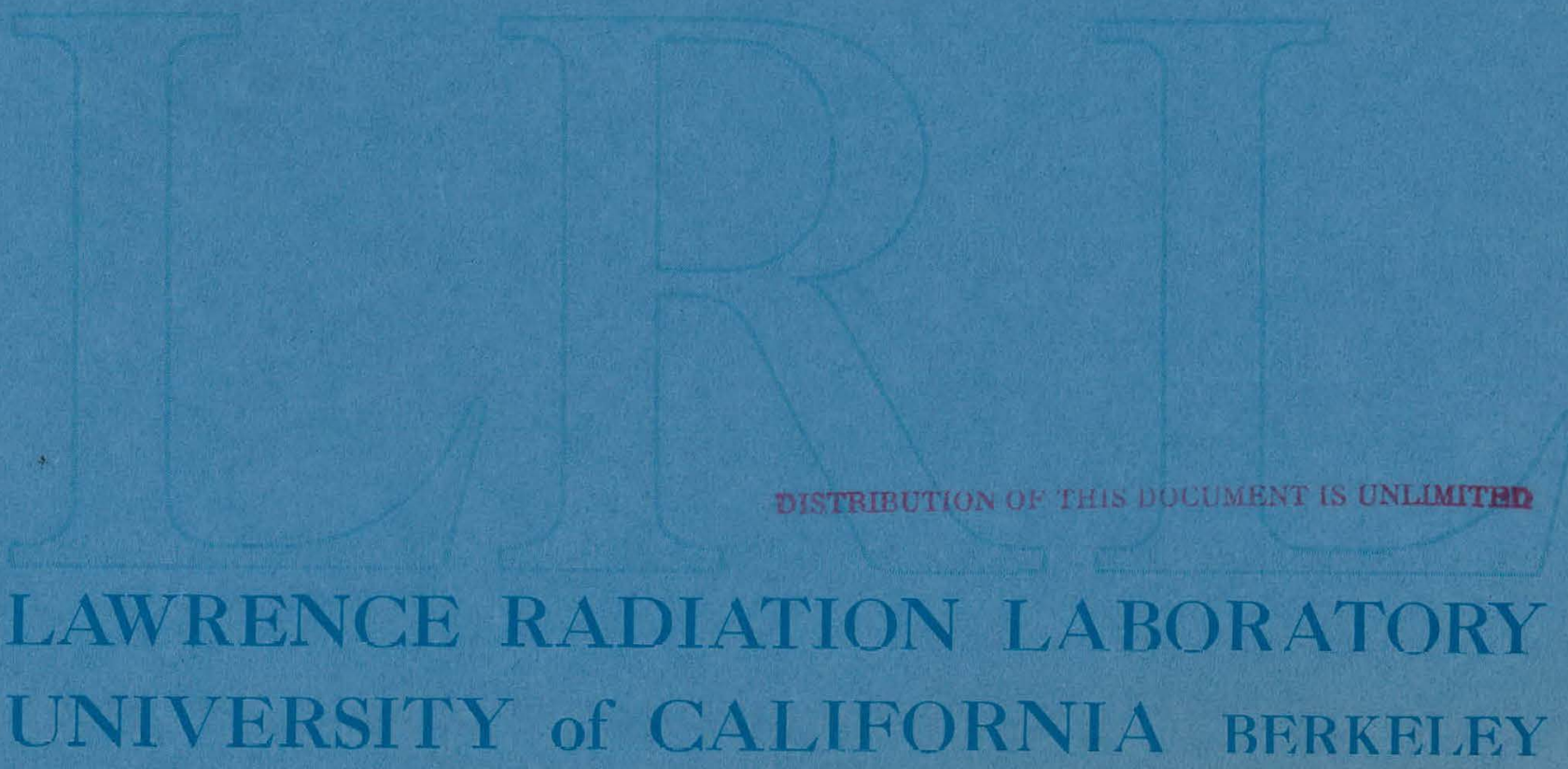




\section{DISCLAIMER}

This report was prepared as an account of work sponsored by an agency of the United States Government. Neither the United States Government nor any agency Thereof, nor any of their employees, makes any warranty, express or implied, or assumes any legal liability or responsibility for the accuracy, completeness, or usefulness of any information, apparatus, product, or process disclosed, or represents that its use would not infringe privately owned rights. Reference herein to any specific commercial product, process, or service by trade name, trademark, manufacturer, or otherwise does not necessarily constitute or imply its endorsement, recommendation, or favoring by the United States Government or any agency thereof. The views and opinions of authors expressed herein do not necessarily state or reflect those of the United States Government or any agency thereof. 


\section{DISCLAIMER}

Portions of this document may be illegible in electronic image products. Images are produced from the best available original document. 


\title{
THE $A_{2}$ AND THE $2^{+}$NONET.
} CONSISTENCY OF DATA

Angela Barbaro-Galtieri

Lawrence Radiation Laboratory

University of California

Berkeley, California

LEGAL NOTICE

This report was prepared as an account of work sponsored by the United States Government. Neither the United States nor the United States Atomic Energy Commission, nor any of their employees, nor any of their contractors, subcontractors, or their employees, makes any warranty, express or implied, or assumes any legal liability or responsibility for the accuracy, completeness or usefulness of any information, apparatus, pleteness or usefulness of any information, apparatus,
product or process disclosed, or represents that its use would not infringe privately owned rights.

\section{ABSTRACT}

New data on the $\mathrm{A}_{2}^{+}$meson fail to show the two-peak structure seen in the $A_{2}^{-}$experiments of the CERN group. All the. bubble chamber experiments on $A_{2}$ production are reviewed and the new data are compared with the CERN data. The two-parameter double-pole formula used to fit the CERN data does not appear to explain the new data. Therefore the only way to reconcile the various experiments on the charged $A_{2}$ is to as sume the presence of two coherently produced resonances with $\mathrm{J}^{\mathrm{P}}=2^{+}$, with a phase depending on either the charge of the incoming beam, or the momentum transfer to the target proton, or the incident momentum, or all three. The $K^{*}(1420)$ and the $f$ meson, members of the same $2^{+}$nonet as the $A_{2}$, do not seem to show any structure consistent with the two-parameter double-pole formula.
\end{abstract}

Martin has presented the results of the CERN boson spectrometer (CBS) and the missing-mass spectrometer (MMS) experiments, both of which consistently show structure in the $\mathrm{A}_{2}$ region. ${ }^{1}$. The CBS experiment has seen structure ${ }^{2}$ 
in the $\mathrm{X}^{-}$of the reaction $\pi^{-} \mathrm{p} \rightarrow \mathrm{pX^{- }}$ as well as in the $\mathrm{K}^{-} \mathrm{K}^{0}$ decay of the $A_{2}^{-} \cdot 3$ In this paper I review all the bubble chamber experiments on the charged $A_{2}$, including the new LRL data. 4 In the latter part of this paper I present the LRI group's experimental results of the search for structure in the $K^{*}(1420)$ meson ${ }^{5}$ and the f meson. 6

There are presently reports of split $A_{2}$ from three experiments ${ }^{1,7,8}$ (not six as often mentioned by Maglic ${ }^{9}$ ), of which two are bubble chamber experiments. Many bubble chamber experiments ${ }^{10-13}$ have failed to give conclusive results either way.

Figure 1 shows the results from the CERN $\pi^{-} \mathrm{p} \rightarrow \mathrm{pX}^{-}$experiments. $^{2}$ The curves drawn on the data are labeled:

Two incoherent Breit-Wigner resonances $(B W), P\left(\chi^{2}\right) \leqslant 0.2 \%$;
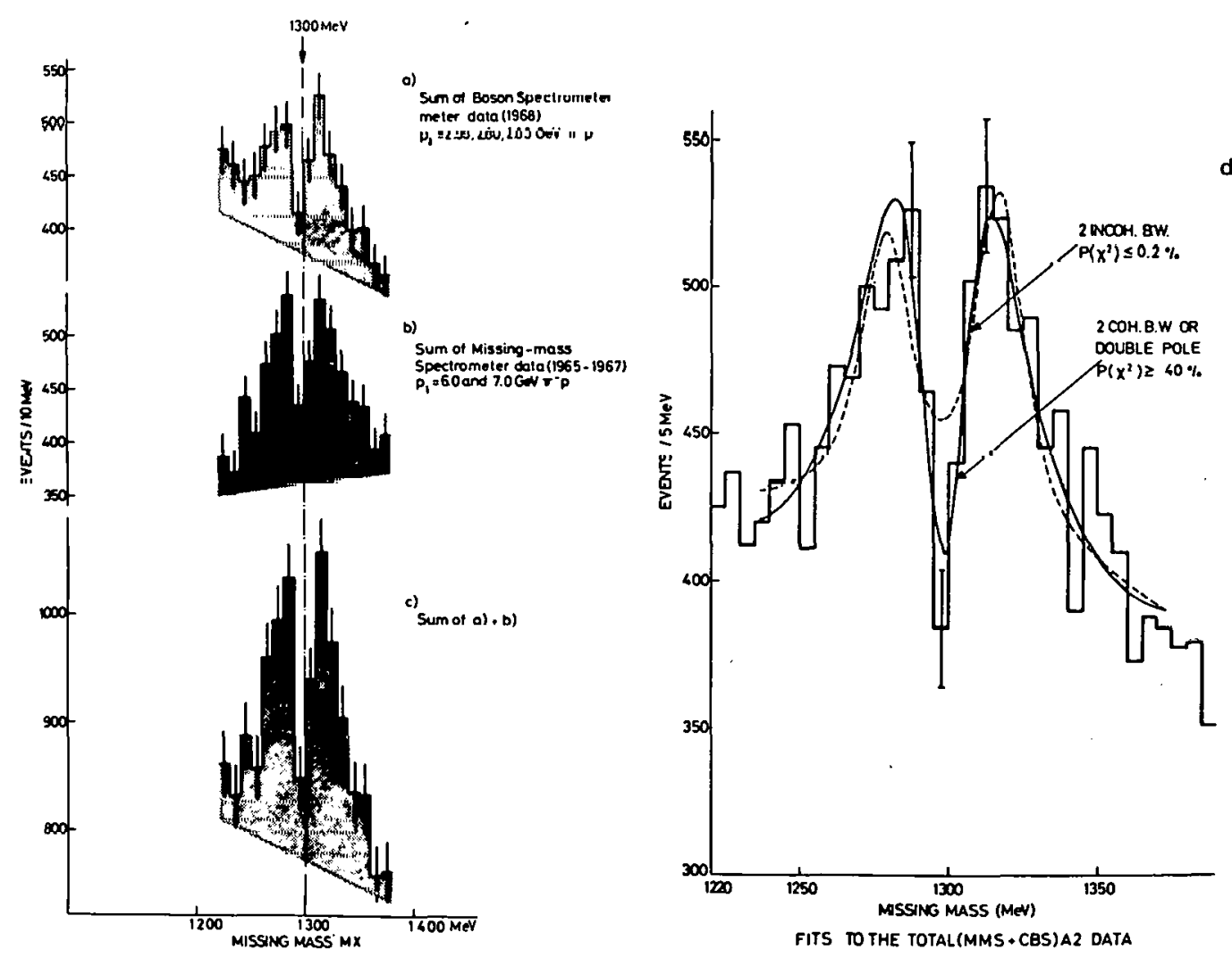

Fig. 1. ( $a, b$, and $c$ ) Evidence for $A_{2}$ splitting from the reaction $\pi^{-} \mathrm{p} \rightarrow \mathrm{pX}^{-}$in the two CERN experiments, (d) the same data plotted in $5-\mathrm{MeV}$ bins and fitted to the various hypotheses. 
Two coherent $B W$ or double pole, $P\left(x^{2}\right) \geqslant 40 \%$.

For two coherent or incoherent BW is usually meant the sum of two complex amplitudes as:

$$
T=\frac{1}{\epsilon_{1}-i}+e^{i \Phi} \frac{1}{\epsilon_{2}-i}
$$

where

$\Phi$ is random for two incoherent BW, i.e., $|\mathrm{T}|^{2}=\left|\mathrm{T}_{1}\right|^{2}+\left|\mathrm{T}_{2}\right|^{2}$

$\Phi$ is fixed for two coherent BW,

$$
\epsilon_{i}=\frac{E-M_{i}}{\Gamma_{i} / 2} \quad \text { (for } i=1,2 \text { ), }
$$

and $M_{i}$ and $\Gamma_{i}$ are mass and width of the ith resonance. The double pole formula, used in the experiments that see the split $\mathrm{A}_{2}$, is

$$
|T|^{2}=\left[\frac{\Gamma\left(M-M_{0}\right)}{\left(M-M_{0}\right)^{2}+(\Gamma / 2)^{2}}\right]^{2} .
$$

This is a two-parameter formula; $M_{0}$ is the mass at which the dip occurs and $\Gamma$ is the width of the double pole (approximately equal to the distance between the two peaks). This formula ${ }^{14}$ has been widely used, and for the one-channel case it can easily be derived by multiplying the $S$ matrices of the two resonances,

$$
S=S_{1} \cdot S_{2}=\left(\frac{\epsilon_{1}-i}{\epsilon_{1}+i}\right)\left(\frac{\epsilon_{2}-i}{\epsilon_{2}+i}\right),
$$

then imposing $\epsilon_{1}=\epsilon_{2}$ (that is, $M_{1}=M_{2}=M_{0}$ and $\Gamma_{1}=\Gamma_{2}=\Gamma_{0}$ ), and finally using $S=1+2 i T$. This formula produces the double peak with a large dip in the middle, as shown in Fig. 1.

This formula is strictly correct only for a one-channel case--that is, a completely elastic resonance. The $\mathrm{A}_{2}$ however, decays in at least three channels, and things may get a lot more complicated. Rebbi and Slansky ${ }^{15}$ have discussed this point and proved that in a many-channel case the shape of a double pole can be completely different: the peaks may have any relative heights, the dip may be anywhere and may even vanish, and the peaks may be double in some channels and single in others. A parameter that 
measures the strength of the dipole introduced by Rebbi and Slansky is $\xi$. This parameter has values

$$
0<\xi<1 \text {, }
$$

and only for $\xi=1$ can one have double peak structure in every channel and can the distributions look very much like the singlechannel case.

It seems to me that the case $\xi=1$ that every experimentalist has been using so far is only one possibility out of a continuum, and it would be unlikely that at every incident energy, every momentum transfer, and every charge of the $\mathrm{A}_{2}$ should one find the same value of $\xi$.

The obvious conclusion of this discussion is that it would be nice if a two-parameter formula such as the one of Eq. (5) were sufficient to explain all the $A_{2}$ data, but it is somewhat unlikely that this is really the case. The experiments we will review in fact indicate that a more complicated structure than Eq. (5) is noodod to crplain all the data.

II CHARGED $A_{2}$ EXPERIMENTS

As discussed in the preceding section, the shape of the $A_{z}$ can depend on the production moohaniom, on tlic incident momentum, and on the momentum transfer. Therefore we have to take all these conditions into consideration in reviewing the experiments.

Tahle I is a summary of five of the cxpcrimcnts that have given any results on the $A_{2}$ splitting (or not splitting). It should be pointed out that there are in addition many bubble chamber experiments that (although with more statistics than some of the experiments listed in Table I) do not show any structure or cannot lead to any conclusion either way. 11-13

Table II is a summary of the rcsonance parameters quoted in the five experiments listed in Table I. 
Table I. Summary of experiments that investigated $A_{2}$ splitting. The reactions studied are $\pi^{ \pm} p \rightarrow p A_{2}^{ \pm}$, except for the last experiment, which is $\mathrm{pp} \rightarrow \mathrm{A}_{2}{ }_{\pi}{ }^{7}$. The columns "Events in peak" and "background signal" have been evaluated by this author. Po stands for "possible, consistent with the data."

\begin{tabular}{|c|c|c|c|c|c|c|c|c|c|c|c|c|}
\hline \multirow[t]{2}{*}{ Reaction } & \multirow{2}{*}{$\begin{array}{l}P_{\text {beam }} \\
(\mathrm{GeV} / \mathrm{c})\end{array}$} & \multirow[t]{2}{*}{ Group } & \multirow[t]{2}{*}{ Ref. } & \multirow[t]{2}{*}{ Method } & \multirow{2}{*}{$\begin{array}{l}\text { Decáy } \\
\text { mode }\end{array}$} & \multirow{2}{*}{$\begin{array}{l}\mathrm{T}_{\mathrm{r}} / 2^{\mathrm{b}} \\
(\mathrm{MeV})\end{array}$} & \multirow{2}{*}{$-{ }^{-t} p p^{c}$} & \multirow{2}{*}{$\begin{array}{c}\text { Events } \\
\text { in } \\
\text { peak }\end{array}$} & \multirow{2}{*}{$\frac{\text { Bkgd. }}{\text { Signal. }}$} & \multicolumn{3}{|c|}{ Probability of fit } \\
\hline & & & & & & & & & & $\mathrm{BW}$ & $\begin{array}{c}\text { Double } \\
\text { pole }\end{array}$ & 2 coh. BW \\
\hline \multirow[t]{3}{*}{$\pi^{-} \mathrm{p}$} & 2.6 & CERN & 2 & $0 \mathrm{deg}$ & $x^{-}$ & 5.2 & $0.09-0.68$ & 1100 & $5 \cdot 3$ & \multirow{2}{*}{$<0.2 \%$} & \multirow{2}{*}{$\geqslant 40 \%$} & \multirow{2}{*}{$\geqslant 40 \%$} \\
\hline & 6,7 & CERN & 16 & Jac. peak & $\mathrm{x}^{-}$ & 16 & $0.20-0.29$ & 1400 & 4.0 & & & \\
\hline & 7 & CERN & 3 & $\mathrm{CBS}$ & $\mathrm{K}^{-} \mathrm{K}_{1}$ & 10 & $0.20-0.29$ & 145 & 0.34 & $1 \%$ & $>60 \%$ & Po \\
\hline \multirow{4}{*}{$\begin{array}{l}\pi^{-} p \\
\pi^{+} p\end{array}$} & 6 & BNL & 10 & $\mathrm{HBC}$ & $\pi^{-} \mathrm{MM}$ & 10 & $0.22-0.39$ & 100 & 1.5 & $\mathrm{Po}^{\mathrm{e}}$ & $\mathrm{Po}^{\mathrm{e}}$ & $\mathrm{Po}^{\mathrm{e}}$ \\
\hline & 7 & LRL & 4 & $\mathrm{HBC}$ & $\rho^{0} \pi^{+}$ & 6.4 & $>0.2^{\mathrm{f}}$ & 833 & 1.4 & $14 \%$ & $0.3 \%$ & Po \\
\hline & \multirow[b]{2}{*}{. } & & & & $\eta \pi^{+}$ & 8.2 & all ${ }^{f}$ & 151 & 0.23 & \multirow{2}{*}{$13 \%$} & \multirow{2}{*}{$0.3 \%$} & \multirow{2}{*}{ Po } \\
\hline & & & & & $\mathrm{K}^{+} \mathrm{K}_{1}$ & 3.6 & $a 11^{f}$ & 101 & 0.34 & & & \\
\hline$\pi^{+} p$ & 5 & BDNP & 7 & $\mathrm{HBC}$ & $\rho^{0} \pi^{t^{1}}$ & 5 & $t^{\prime}>0.1$ & 108 & 1.3 & $20 \%$ & $63 \%$ & Po \\
\hline $\bar{p} p$ & $0,0.7,1.2$ & CPL & 8 & $\mathrm{HBC}$ & $K^{ \pm} K_{1}$ & 5 & --- & 270 & 3.5 & $4 \%$ & $65 \%$ & Po \\
\hline
\end{tabular}

a. $\mathrm{X}^{-}$stands for negative missing mass, MM stands for neutrals.

b. $\Gamma_{\mathbf{r}}$ is the full width of the resolution function at half maximum.

c. $t_{\mathrm{pF}}$ is the four-momentum transfer squared in $(\mathrm{GeV} / \mathrm{c})^{2}$.

d. Events in peak are events above the background quoted jy the authors of the various papers. Both the events in the peak and the background/signal are calculated in the region 1200 to $1400 \mathrm{MeV}$.

e. No probabilities quoted for this experiment. The fits of the first two columns were tried and the authors state that "the two-peak fit is better, although not significantly, than the one-peak fit,"

f. The momentum-transfer distribution of the $\mathrm{A}_{2}$, as seen in the $\mathrm{K}^{\neq} \overline{\mathrm{K}}^{0}$ and $\eta \pi{ }^{7}$ channels, goes to zero rapidly; only $7 \%$ of the events have $-t>0.7(\mathrm{GeV} / \mathrm{c})^{2}$. 
Table II. Summary of parameters quoted by the five groups that have investigated the $A_{2}$ splitting.

\begin{tabular}{|c|c|c|c|c|c|c|c|c|c|}
\hline \multirow{2}{*}{ Experiment } & \multirow{2}{*}{ Decay mode } & \multicolumn{3}{|c|}{$\begin{array}{l}\text { Single } \\
\text { resonance }\end{array}$} & \multicolumn{3}{|c|}{$\begin{array}{c}\text { Double pole } \\
\text { (Eg. 5) }\end{array}$} & \multicolumn{2}{|c|}{$\begin{array}{c}\begin{array}{c}\text { Positions of } \\
\text { peaks }\end{array} \\
\end{array}$} \\
\hline & & $\bar{M}$ & $\Gamma$ & $F\left(x^{2}\right)$ & $\bar{M}$ & $\Gamma$ & $P\left(x^{2}\right)$ & $\mathrm{A}_{2 \mathrm{~L}}$ & $\mathrm{~A}_{2 \mathrm{H}}$ \\
\hline \multirow[t]{2}{*}{ CERN } & $x^{-}$ & $\cdots$ & $\cdots$ & -- & $\begin{array}{r}1298 \\
\pm 5\end{array}$ & $\begin{array}{l}28 \\
\pm 5\end{array}$ & $40 \%$ & $\begin{array}{r}1278 \\
\pm 5\end{array}$ & $\begin{array}{r}1318 \\
\pm 5\end{array}$ \\
\hline & $\mathrm{K}^{-} \mathrm{K}_{1}$ & $-\cdots$ & --- & $\ldots$ & $\begin{array}{r}1300 \\
\pm 5\end{array}$ & $\begin{array}{l}32 \\
\pm 5\end{array}$ & $60 \%$ & $\begin{array}{r}1276 \\
\pm 6\end{array}$ & $\begin{array}{r}1323 \\
\pm 6\end{array}$ \\
\hline$B N L^{b}$ & $\pi^{-} \mathrm{MM}$ & $\begin{array}{r}1287 \\
\pm 10\end{array}$ & $\begin{array}{r}94 \\
+30 \\
-20\end{array}$ & & --- & -- & --- & $\begin{array}{r}1269 \\
\pm 5\end{array}$ & $\begin{array}{r}1315 \\
\pm 5\end{array}$ \\
\hline \multirow[t]{2}{*}{$L_{R} L^{c}$} & $\rho^{0} \pi^{+}$ & $\begin{array}{r}1304 \\
\pm 5\end{array}$ & $\begin{array}{r}82 \\
\pm 13\end{array}$ & $14 \%$ & $\begin{array}{r}1298 \\
\pm 4\end{array}$ & $\begin{array}{l}21 \\
\pm 4\end{array}$ & $0.3 \%$ & $\cdots$ & -- \\
\hline & $K^{+} K_{1}+\eta \pi^{+}$ & $\begin{array}{r}1309 \\
\pm 6\end{array}$ & $\begin{array}{l}100 \\
\pm 15\end{array}$ & $13 \%$ & $\begin{array}{r}1305 \\
\pm 4\end{array}$ & $\begin{array}{l}30 \\
\pm 4\end{array}$ & $0.3 \pi$ & --- & $\ldots$ \\
\hline BDNP & $\rho^{0}{ }^{+}$ & $\begin{array}{r}1308 \\
\pm 12\end{array}$ & $\begin{array}{l}139 \\
\pm 50\end{array}$ & $20 \%$ & $\begin{array}{r}1306 \\
\pm 4\end{array}$ & $\begin{array}{l}41 \\
\pm 5\end{array}$ & $63 \%$ & $\begin{array}{r}1275 \\
\pm 6\end{array}$ & $\begin{array}{r}1338 \\
\pm 4\end{array}$ \\
\hline C.PL & $\mathbf{K}^{ \pm} \mathbf{K}_{1}$ & $\begin{array}{r}1296 \\
\pm 7\end{array}$ & $\begin{array}{r}124 \\
+41 \\
-27\end{array}$ & $4 \%$ & $\begin{array}{r}1303 \\
\pm 2\end{array}$ & $\begin{array}{l}31 \\
\pm 4\end{array}$ & $65 \%$ & $\begin{array}{r}1281 \\
\pm 3\end{array}$ & $\begin{array}{r}1325 \\
\pm 3\end{array}$ \\
\hline ' & & & & & & & & & . \\
\hline
\end{tabular}

a. Values quoted here are results of fits assuming twn incoherent DreitWigner resonances.

b. See footnote (e) of Table I; single-resonance and two-resonance fits both give good probability.

c. The probabilities quoted for this experiment are calculated in the region 1200 to $1400 \mathrm{MeV}$.

\section{A. $\pi^{-}$p EXPERIMENTS}

CERN experiment. The first experiment to show a double-polelike structure was the MMS experiment in 1966, included in ref.

2. Figure 1 shows all of the CERN data for the reaction

$$
\pi^{-} \mathrm{p} \rightarrow \mathrm{pX}^{-}
$$

The momenta studied were $2.55,2.60$, and $2.65 \mathrm{GeV} / \mathrm{c}$ in the C.BS experiment and 6.0 and $7.0 \mathrm{GeV} / \mathrm{c}$ in the MMS experiment. At the first Philadelphia Conference Kienzle ${ }^{16}$ reviewed these data; since 
then various groups have been searching for an effect as dramatic as that shown in Fig. 1.

The CERN group found the same effect again in their $\mathrm{K}^{-} \mathrm{K}_{1}$ mass distribution shown in Fig. 2. This experiment, too, is described by Martin, ${ }^{1}$ to whom we refer for details. Table I contains a summary of the characteristics of this experiment: the resolution, the momentum-transfer region, the size of the signal, and the probabilities for various fits. Table II shows the values of the parameters obtained by fitting the data to various hypotheses, and Table III shows the details of the fits to the data of Fig. 1d. It is interesting to notice that the two-coherent-resonances hypothesis has two solutions equally good: (a) a symmetric solution, i. e., two narrow resonances, (b) a broad-narrow solution, i.e., a wide resonance and a narrow one with the same mass. We will come back to this point later.

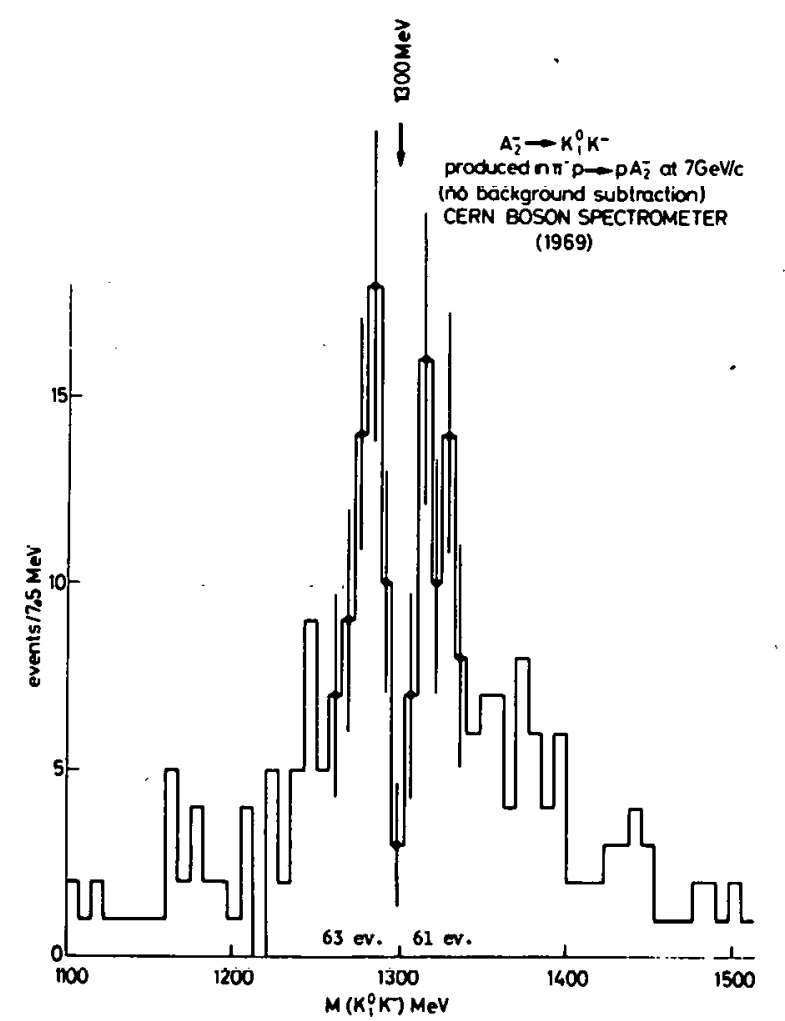

Fig. 2. The $\mathrm{K}^{-} \mathrm{K}_{1}$ decay mode of the $\mathrm{A}_{2}$ - as seen by the CERN (CBS) experiment at $7 \mathrm{GeV} / \mathrm{c}$. 
Table III. Results of various fits to the $A_{2}$ data in the reaction $\pi^{-} \mathrm{p} \rightarrow \mathrm{pX}^{-}$done by the CERN group. 2

Double peak fits to the total (MMS + CBS) split $A_{2}$ (Onoertainty in mass $\Delta M= \pm 5 \mathrm{MeV}$; in width $\Delta \Gamma= \pm 5 \mathrm{MeV}$ )

\begin{tabular}{|c|c|c|c|}
\hline Hypothesis & $\begin{array}{l}M_{1} \\
\Gamma_{1}\end{array}$ & $\begin{array}{l}u_{2} \\
\Gamma_{2}\end{array}$ & $P\left(x^{2}\right)$ \\
\hline 2 incoherent B.W. & $\begin{array}{r}1278 \\
22\end{array}$ & $\begin{array}{r}1318 \\
21\end{array}$ & $\leqslant \underline{0.2 \%}$ \\
\hline $\begin{array}{l}2 \text { coherent B.W. } \\
\text { sym. solution }\end{array}$ & $\begin{array}{r}1289 \\
22\end{array}$ & $\begin{array}{r}1309 \\
22\end{array}$ & $\geqslant 40 \%$ \\
\hline $\begin{array}{l}\text { asym. solution } \\
\text { (broad-narrow) }\end{array}$ & $\begin{array}{r}1298 \\
90\end{array}$ & $\begin{array}{r}1297 \\
12\end{array}$ & $\geqslant 40 \%$ \\
\hline "Double Pole" & & $\begin{array}{r}298 \\
28\end{array}$ & $\geqslant 40 \%$ \\
\hline
\end{tabular}

BNL experiment. Crennell et al. ${ }^{10}$ have looked at the reaction

$$
\pi^{-} \mathrm{p} \rightarrow \mathrm{p} \pi^{-} \mathrm{MM} \quad \text { at } 6.0 \mathrm{GeV} / \mathrm{c} \text {. }
$$

Their best resolution region is for proton momenta between 0.485 and $0.660 \mathrm{GeV} / \mathrm{c}$, corresponding to the momentum transfer region reported in Table $I$. The $\pi^{-} \mathrm{MM}$ plot for this region is shown in Fig. 3. There are 100 events above 150 background events. The values of the parameters for the various fits are shown in Table II; however, the authors do not quote $\chi^{2}$ probabilities and state "The two-peak fit is better, although not significantly, than the one-peak fit." So we take these data as not giving evidence either way. No additional information from the $K^{-} K^{0}$ or the $\eta \pi^{-}$(with $\eta$ decaying into $\pi^{+} \pi^{-} \pi^{0}$ ) decays of the $A_{2}$ is available from this experiment. 
B. $\pi^{+} \mathrm{p}$ EXPERIMENTS

LRL experiment. ${ }^{4}$ This is the bubble chamber experiment with the largest statistics. The reactions studied at $7 \mathrm{GeV} / \mathrm{c}$ are

$$
\begin{array}{lll}
\pi^{+} \mathrm{p} \mathrm{p} \mathrm{A}_{2}^{+}, & \mathrm{A}_{2}^{+} \rightarrow \mathrm{K}^{+} \mathrm{K}_{1} & \text { (133), } \\
& \mathrm{A}_{2}^{+} \rightarrow \eta \pi^{+} & \text {(185), } \\
& \mathrm{A}_{2}^{+} \rightarrow \mathrm{p}^{+} \pi^{+} & \text {(1988), }
\end{array}
$$

where the number in parentheses indicates the total number of events in the 1200 - to $1400-\mathrm{MeV}$ region for each of the three reactions. For reactions $(7 \mathrm{~b})$ and $(7 \mathrm{c})$ the events in the $\Delta^{++}$band $\left(\mathrm{M}_{\pi^{+}}<1.38 \mathrm{GeV}\right)$ have been removed from the sample in order to reduce the background. The $\mathrm{K}^{+} \mathrm{K}_{1}$ and $\eta \pi^{+}$signal are for the first time seen clearly and with large statistics in a bubble chamber experiment, as shown in Fig. $4 \mathrm{a}$ and $4 \mathrm{c}$. For the $\rho^{0} \pi^{+}$decay an additional cut was made, i.e., only events with momentum

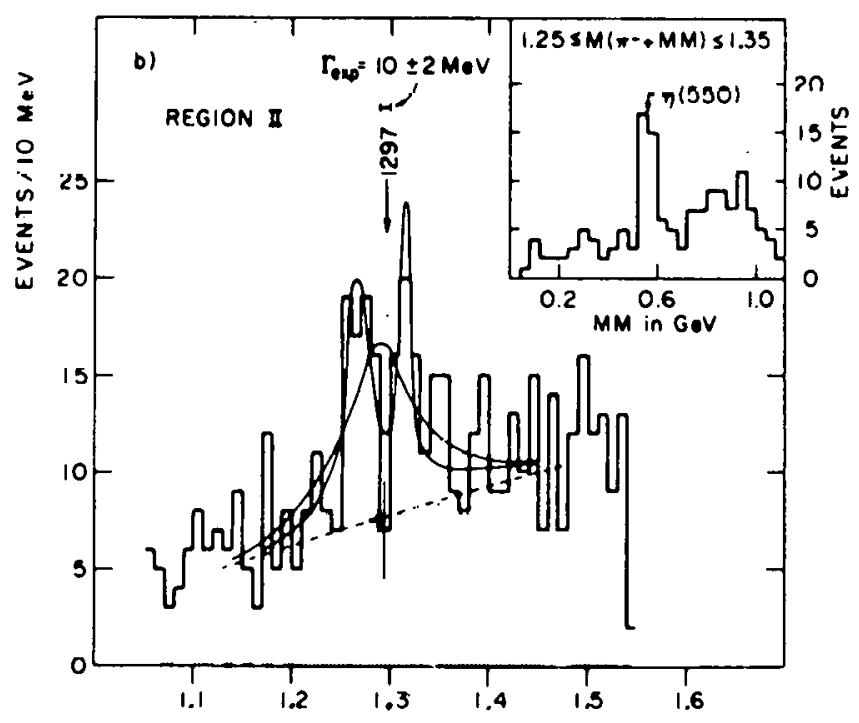

Fig. 3. The data of Crennell etal. (Ref, 10) for the reaction $\pi{ }^{-} \mathrm{p} \rightarrow \mathrm{p} \pi^{-\mathrm{MM}}$ at $6 \mathrm{GeV} / \mathrm{c}$ when the condition $0.485<\mathrm{P}_{\mathrm{p}}$ $<0.660 \mathrm{GeV} / \mathrm{c}$ was imposed. The insert shows the MM distribution. The curves correspond to a singleBreit-Wigner ( $\mathrm{BW}$ ) resonance fit and to two-incoherentBW fit. Both hypotheses fit reasonably well, although the two-peak hypothesis fits better. 
transfer $-t>0.2(\mathrm{GeV} / \mathrm{c})^{2}$ have been included. This cut was imposed in order to reduce the background coming from the low $\rho \pi$ mass enhancement due to diffraction scattering (usually called diffractive $A_{1}$ production). For $-t>0.2$ the $A_{2}$ signal (Fig. 4c) stands above an almost flat background. In Fig. 4c the $\pi^{+} \pi^{-} \pi^{+}$invariant mass is shown instead of the $\rho^{0} \pi^{+}$in order to avoid distortion of phase space due to the well-known crossing bands effect. ${ }^{17}$ In fact, at the $A_{2}$ mass most of the Dalitz plot is still covered with p. From the Dalitz plot of the $\mathrm{A}_{2}$ region (1200-1400 MeV), it is estimated that $90 \%$ of the events of Fig. $4 \mathrm{c}$ in the $\mathrm{A}_{2}$ region are $\rho^{0}$ events.
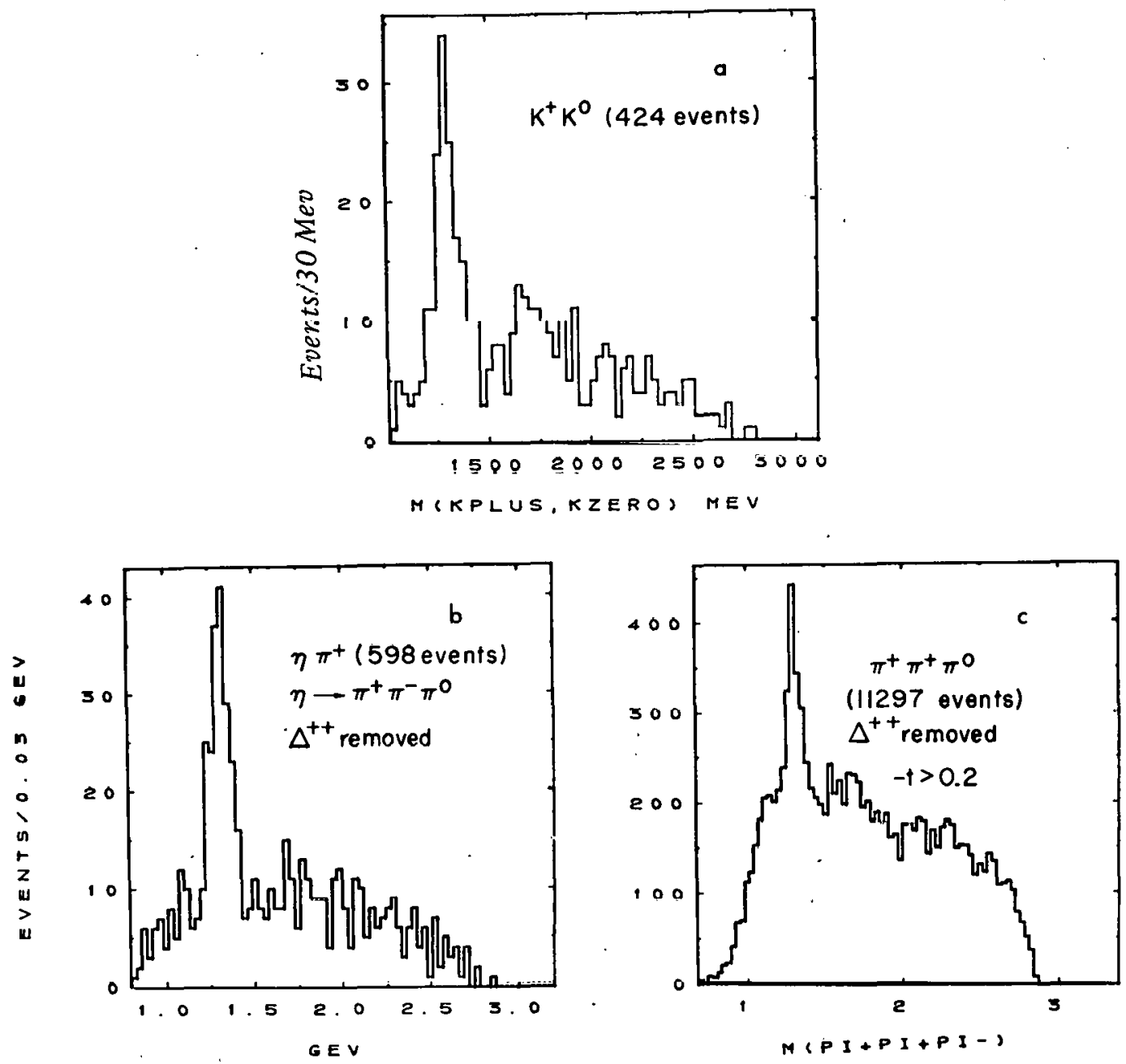

Fig, 4, Results of the LRL experiment at $7 \mathrm{GeV} / \mathrm{c}$. Mass plots for (a) $K^{+} K_{1}$, (b) $\eta \pi^{+}$, (c) $\pi^{+} \pi^{-} \pi^{+}$. 
The resolution of this experiment is very good; as seen from Table $\mathrm{I}$, it is $3.6 \mathrm{MeV}$ for the $\mathrm{K}^{+} \mathrm{K}_{1}$ channel and goes up to $8.2 \mathrm{MeV}$ for the $\eta \pi^{+}$channel. Figure 5 shows the $\eta$ signal for the events of Fig. 4b. The curve drawn on it is the calculated resolution, which agrees very well with the histogram, which is in fact the measured resolution. This is only one of the many tests done to check the resolution (we refer the reader to Ref. 4 for more details).

Figure 6 and 7 show the fit of the two hypotheses (BW and the double pole of Eq. 5) to the data. Figure 6 shows the $\rho^{0} \pi^{+}$data and Fig. 7 the $\mathrm{K}^{+} \mathrm{K}_{1}$ and $n \pi^{+}$data together. The results of the fits are given in Tables I and II. The double-pole fit is bad in both samples; its probability with respect to the one resonance hypothesis in the region 1200 to $1400 \mathrm{MeV}$ is $0.16 \%$ and $0.18 \%$ for

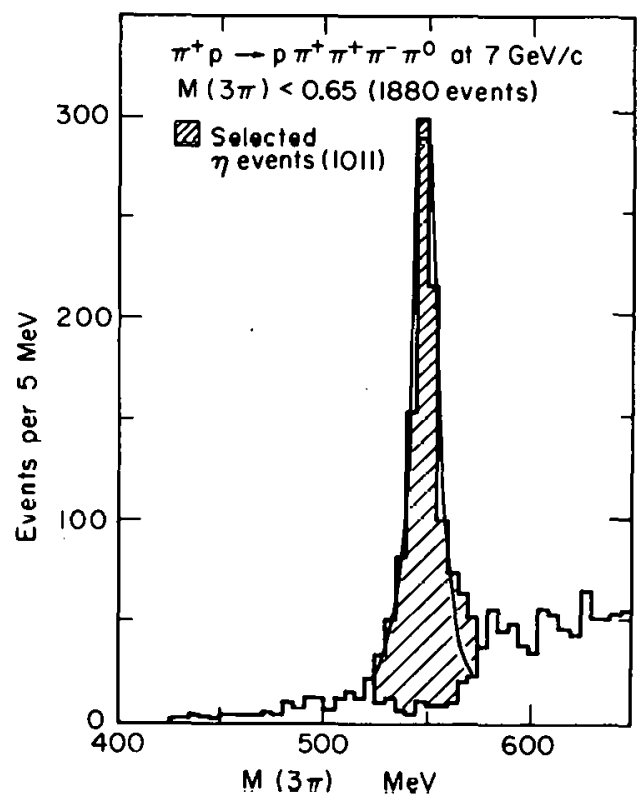

Fig. 5. The $\eta$ signal in the LRL data at $7.0 \mathrm{GeV} / \mathrm{c}$. Shaded area shows $\eta$ events selected for the plot of Fig. $4 b$ by fitting the events to $\pi^{+} \mathrm{p} \rightarrow \mathrm{p} \pi^{+} \eta$ and then fitting the decay $\eta \rightarrow \pi^{+} \pi^{-} \pi^{0} .4$ Curve drawn on histogram is the calculated resolution. $\left(\Gamma_{\mathrm{r}} / 2=6.2 \mathrm{MeV}\right)$ 
Figs. 6 and 7 respectively calculated by evaluating the ratio of the likelihoods of the fits. In each case the appropriate mass resolution has been folded in with the matrix element form.

It should be pointed out here that these probabilities depend on the mass interval that has been fitted. For a smaller mass interval the background can be badly estimated; although the fit in the resonance region might be better, it might not represent the real situation. The background was fitted over the region shown in Fige: 6 and 7.

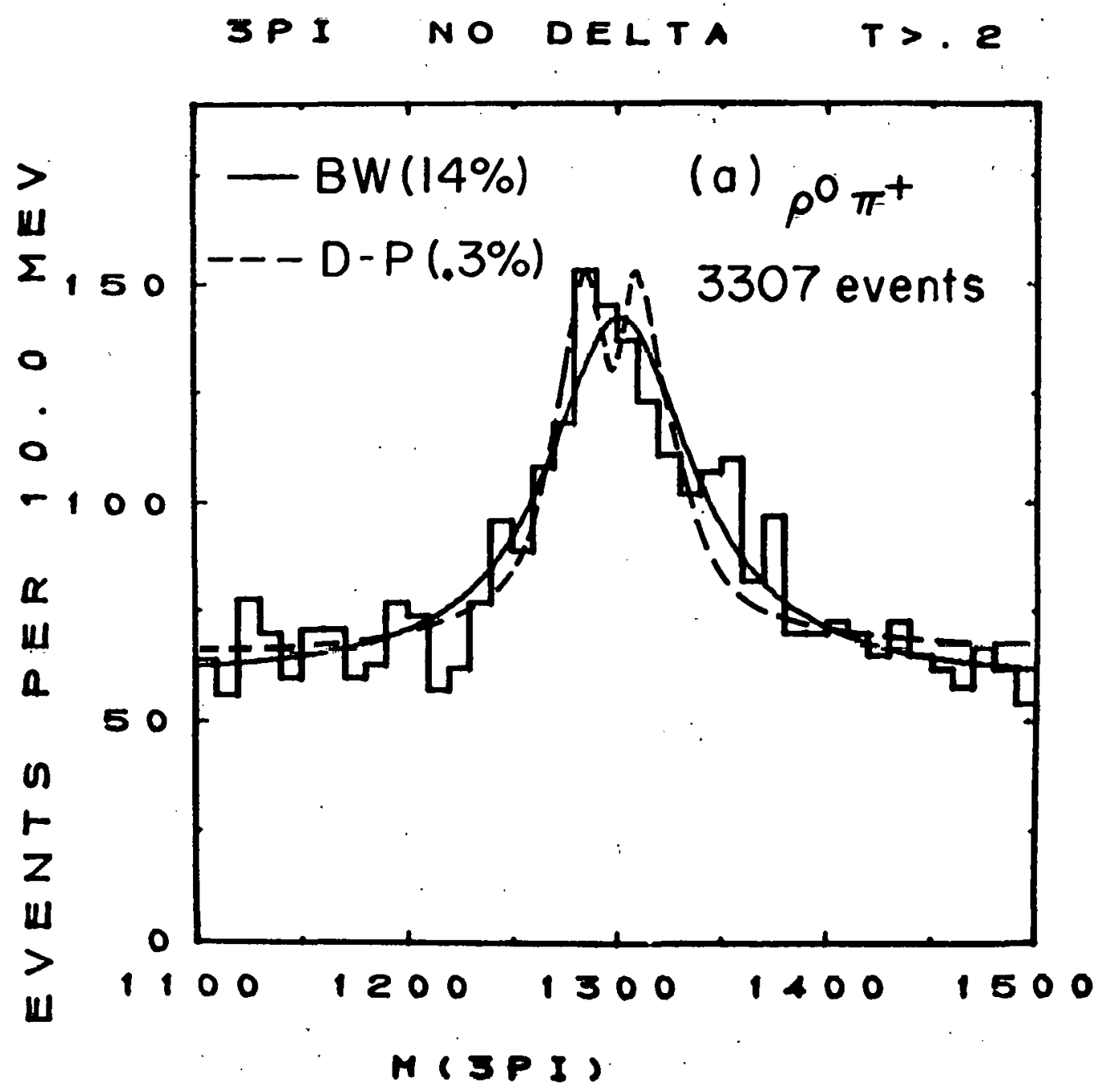

Fig. 6. Fits to the LRL data (Ref. 4) for the $p^{0} \pi^{+}$decay of the $A_{2}$. Solid line is best fit obtained for a BW resonance, dashed line is the best fit for the double-pole hypothesis (Eq. 5). 


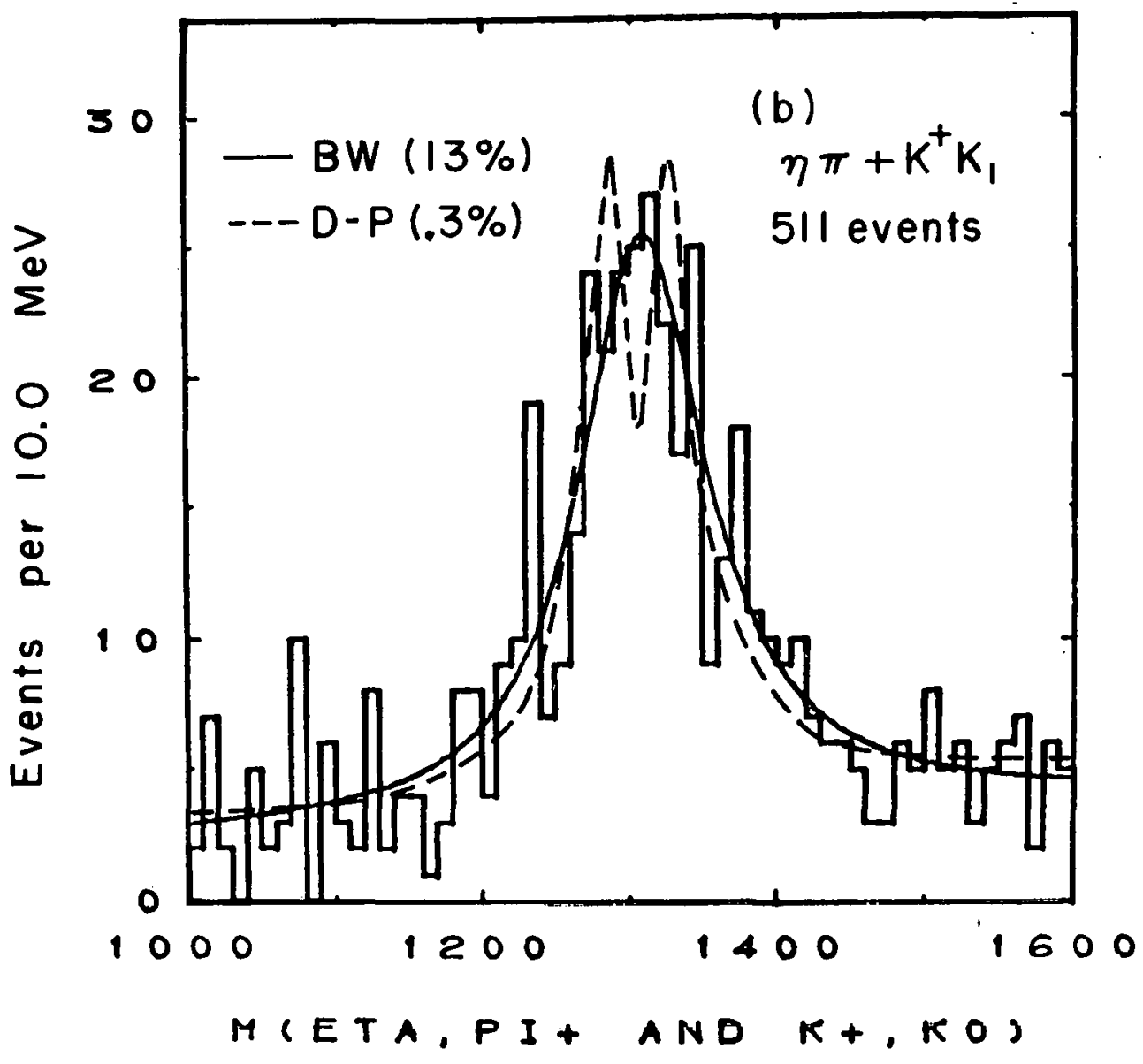

Fig. 7. Fits to the LRL data (Ref. 4) for the $\mathrm{K}^{+} \mathrm{K}_{1}$ and $\eta \pi^{+}$ decays of the $A_{2}$. Solid line is best fit obtained for a $B W$ resonance, dashed line is the best fit for the double-pole hypothesis (Eq. 5).

Various fits were tried for two coherent BW's, and since no separate peaks are present in the data, the values of the two masses, if left free, tend to fall at the same place. Fits using the CERN parameters of Table III and letting the relative heights of the two resonances as well as the phases vary, give a reasonably good $\chi^{2}$. However, these data need only one $B W$ and cannot give any results on the two-coherent-resonances hypothesis other than that it is compatible with the data. 
The BDNPT experiment. ? The 5-GeV/c experiment of Böckman et al. shows some structure in the $\rho^{0} \pi^{+}$data when the $\left(t-t_{\text {min }}\right)$ $<0.1$ cut is made. Figure 8 shows the data. An inspection of Table I and Fig. 6 shows that the data of this experiment are about $1 / 8$ of the LRL experiment. The probabilities, shown in the caption, for the resonance fit and the double-pole fit are almost equally good, so I would say the evidence for a split $\mathrm{A}_{2}$ from this experiment is weak. The fit for two incoherent BW's gave $70 \%$ probability, with the masses quoted in Table II and widths $\Gamma_{1}=27 \pm 13, \Gamma_{2}=17 \pm 15 \mathrm{MeV}$.

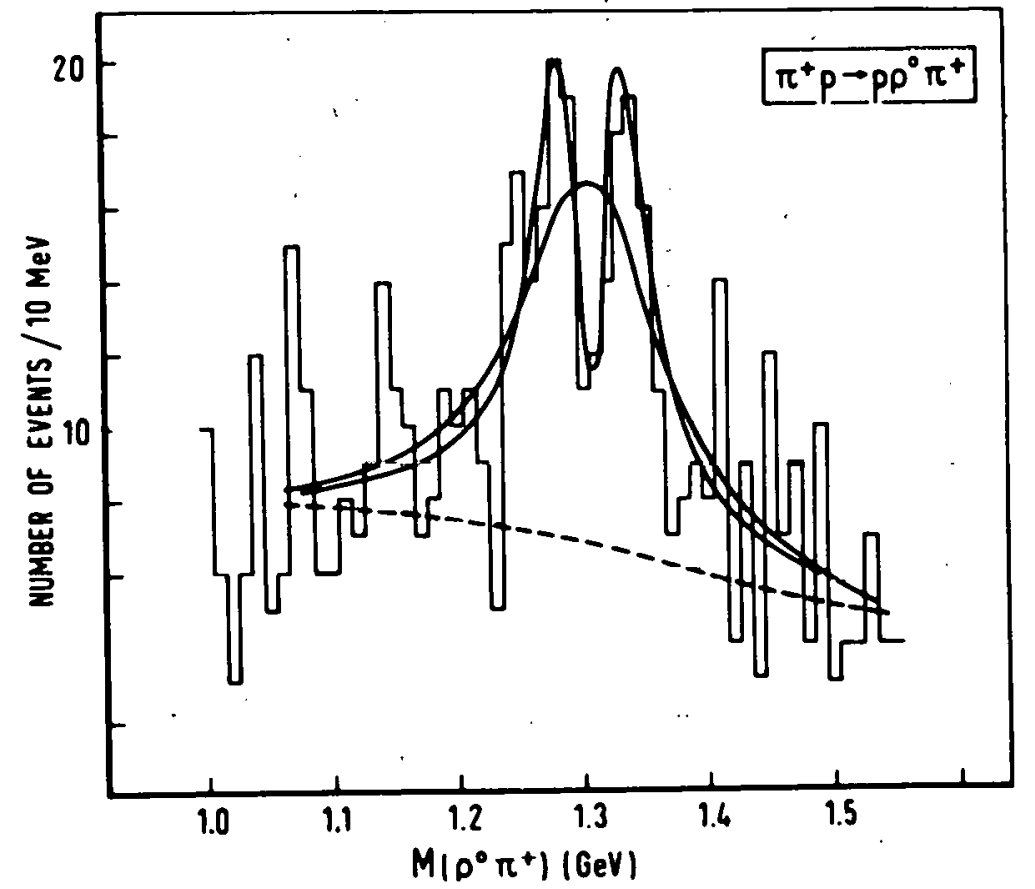

Fig. 8. Data of Böckman et al. (Ref. 7) at $5.0 \mathrm{GeV} / \mathrm{c}$. The two curves correspond to one BW fit (smooth curve, $20 \%$ probability) and to a double-pole fit (Eq. 5, $63 \%$ probability).

\section{INCIDENT BEAMS OTHER THAN PIONS}

The $\bar{p}$ p experiment of Aguilar-Benitez et al. ${ }^{8}$ shows structure in the $K^{ \pm} K_{1}$ mass plot, as shown in Fig. 9. The results of the fits. 
to these data favor the double-pole hypothesis. Again Eq. (5) has been used, and the results are shown in Tables I and II. The fit for two incoherent BW's gives a $28 \%$ probability with the masses reported in Table II and widths of $22+10 \mathrm{MeV}$ for both, It seems to me that this is the only experiment that supports the split $A_{2}$ hypothesis of the CERN experiments.

In addition to the $\bar{p} p$ experiment, another observation of charged $A_{2}$ in a non-pion beam has been reported by $\mathrm{Crennell}$ et al. ${ }^{18}$ The reaction studied was $\mathrm{K}^{-} \mathrm{n} \rightarrow \Lambda_{\rho}{ }^{-}$, and a narrow peak $(\Gamma \approx 40 \mathrm{MeV}$ ) at a mass of $1289 \pm 10 \mathrm{MeV}$ was observed. I do not include this observation in this discussion for two reasons: (a) It is a completely different reaction with different produc tion mechanism. (b) The statistics involved in the experiment

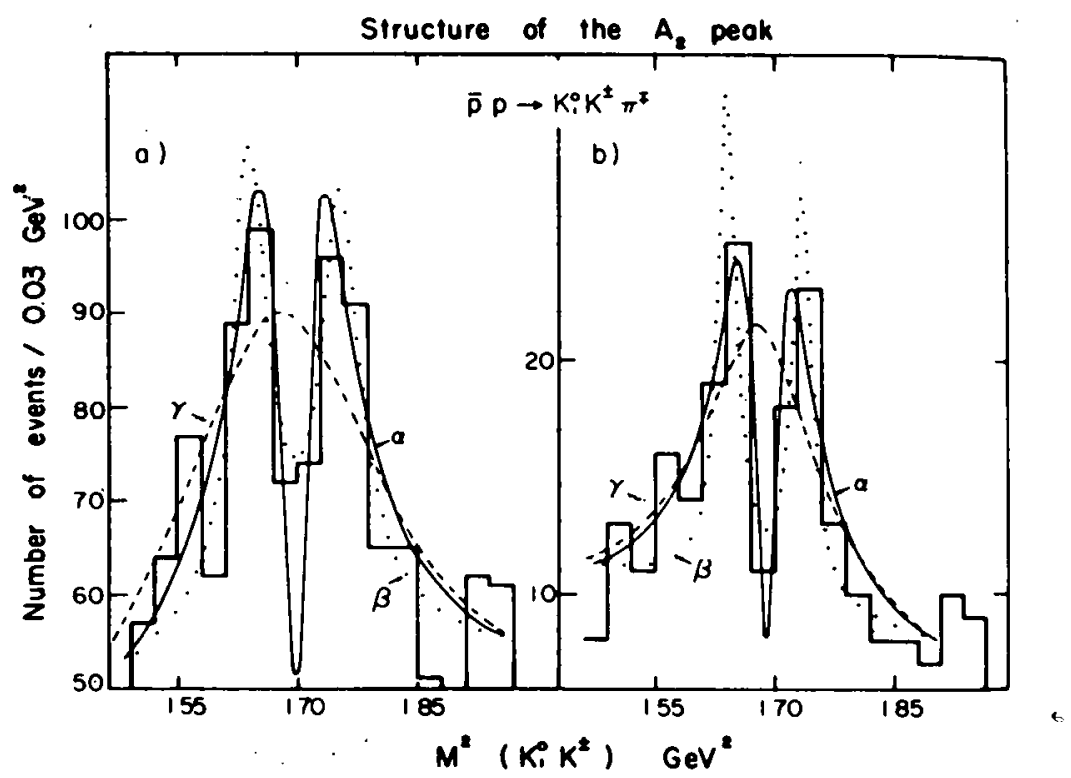

Fig. 9. Data of Aguilar-Benitez et al. (Ref. 8): (a) all antiproton momenta included $(0,0.7,1.2 \mathrm{GeV} / \mathrm{c})$, note the suppressed scale in this plot; (b) the $0.7 \mathrm{GeV} / \mathrm{c}$ data only. The curves correspond to the various hypotheses: $(\alpha)$ double-pole $(65 \%),(\beta)$ incoherent sum of two BW's $(28 \%)$, and $(\gamma)$ single $\mathrm{BW}(4 \%)$. Percentages in parentheses refer to plot (a). 
are less than any of the experiments discussed so far; the effect is at most 40 events on a background of 60 events.

The two experiments that can be directly compared are the CERN and LRL experiments, because they both use a pion incident beam and have the largest statistics. As shown in Table I, apart from the fact that the charge of the incident beam is different, the other major difference, that has been argued about during this Conference, is in the momentum transfer detected by the two experiments. Let me try to make some comparisons. Table IV is a summary of these comparisons.

Table IV. Comparison of the CERN (Ref. 1) and LRI (Ref. 4) experiments on charged $A_{2}$ production in the reactions $\pi=p \rightarrow p \Lambda_{2}^{\mp}$. $\Gamma_{p}$ is the momentum of the proton in the laboratory system; $-t_{p p}$ is the four-momentum transfer squared to the proton.

\begin{tabular}{|c|c|c|c|c|c|c|c|c|c|}
\hline & $\begin{array}{l}\text { Exper - } \\
\text { iment }\end{array}$ & Dearit & $\begin{array}{c}\mathrm{P}_{\pi} \\
(\mathrm{GeV} / \mathrm{c})\end{array}$ & Decay & $(\mathrm{GeV} / \mathrm{P} / \mathrm{c})$ & $\begin{array}{l}-\mathrm{pp}^{\mathrm{pp}} \\
(\mathrm{GeV} / \mathrm{c})^{2}\end{array}$ & $\begin{array}{l}\text { Events }{ }^{a} \\
\text { in peak }\end{array}$ & $\begin{array}{l}\text { Back- } \\
\text { ground }\end{array}$ & Oorrunests \\
\hline \multirow{2}{*}{ Sarne. $P_{\pi}$} & CERN & $\pi^{-}$ & 6.7 & $x^{-}$ & $0.46-0.56$ & $0.20-0.29$ & 1400 & 5660 & split $A_{2}$ \\
\hline & LRL & $\pi^{+}$ & 7 & $p^{0} \pi^{+}$ & $>0.32$ & $>0.10$ & 1132 & 1943 & smooth $\mathrm{A}_{2}$ \\
\hline Same $\mathrm{P}_{\pi}, \mathrm{t}$ & LRL & $\pi^{+}$ & 7 & $\rho^{0} \pi^{+}$ & $0.46-0.56$ & $0.20-0.29$ & 273 & 497 & smooth $\mathrm{A}_{2}$ \\
\hline \multirow[t]{2}{*}{$\mathrm{K}^{ \pm} \overline{\mathbf{K}}^{0}$} & CERN & $\pi^{-}$ & 7 & $\mathrm{~K}^{-} \mathrm{K}^{0}$ & $0.46-0.56$ & $0.20-0.29$ & 145 & 50 & split $A_{2}$ \\
\hline & LRL & $\pi^{+}$ & 7 & $\mathrm{~K}^{+} \mathbf{K}^{0}$ & all & all & 101 & 34 & smooth $\mathrm{A}_{2}$ \\
\hline
\end{tabular}

a. Events in the region $1200-1400 \mathrm{MeV}$.

Same incident momentum. The MSS experiment was done at 6 and at $7 \mathrm{GeV} / \mathrm{c}$, the LRL one at $7 \mathrm{GeV} / \mathrm{c}$. Figure 10 shows the comparison of these two experiments which were done at similar incident momentum. Notice that the number of events in the peak is somewhat comparable, although, since the CERN apparatus detects only the proton in the final state, their background is much worse. This plot shows that for a given incident momentum the CERN and LRL data are different, therefore 


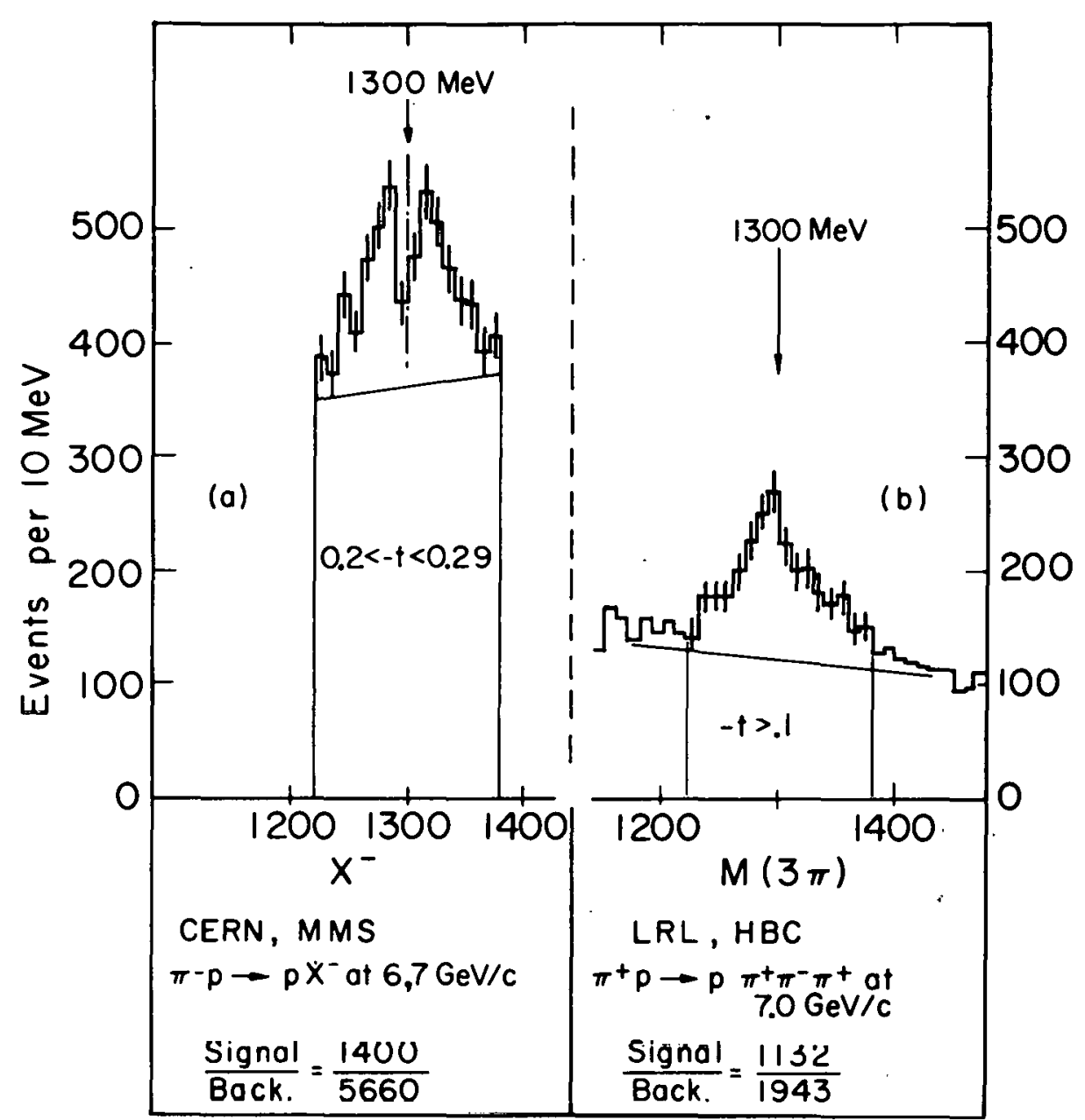

Fig. 10. Comparison of CERN and LRL data at the same incident pion momentum. (a) CERN data (resolution $\Gamma_{\mathbf{r}} / 2=8$ $\mathrm{MeV}),(\mathrm{b})$ LRL data $\left(\Gamma_{\mathrm{r}} / 2=6.4 \mathrm{MeV}\right) . \quad$ :

the splitting of the $A_{2}$ depends upon some other variable, the incident momentum alone does not seem to explain the effect. As shown in Table IV the CERN data were taken in a small momentum transfer region, the $L R L$ data include all momentum transfers. Calling ${ }{ }_{C}$ the momentum transfer of the CERN experiment, the LRL data shows a ratio of events below $/ \mathrm{t}_{\mathrm{C}} /$ above equal to $1.5 / 1 / 2$.

Same incident momentum, same $t$. The statistics of the LRL data get small if the same $t$ cuts as CERN are required. The LRL data with the same $t$ cuto as CERN are shown in Fig. 11. There 


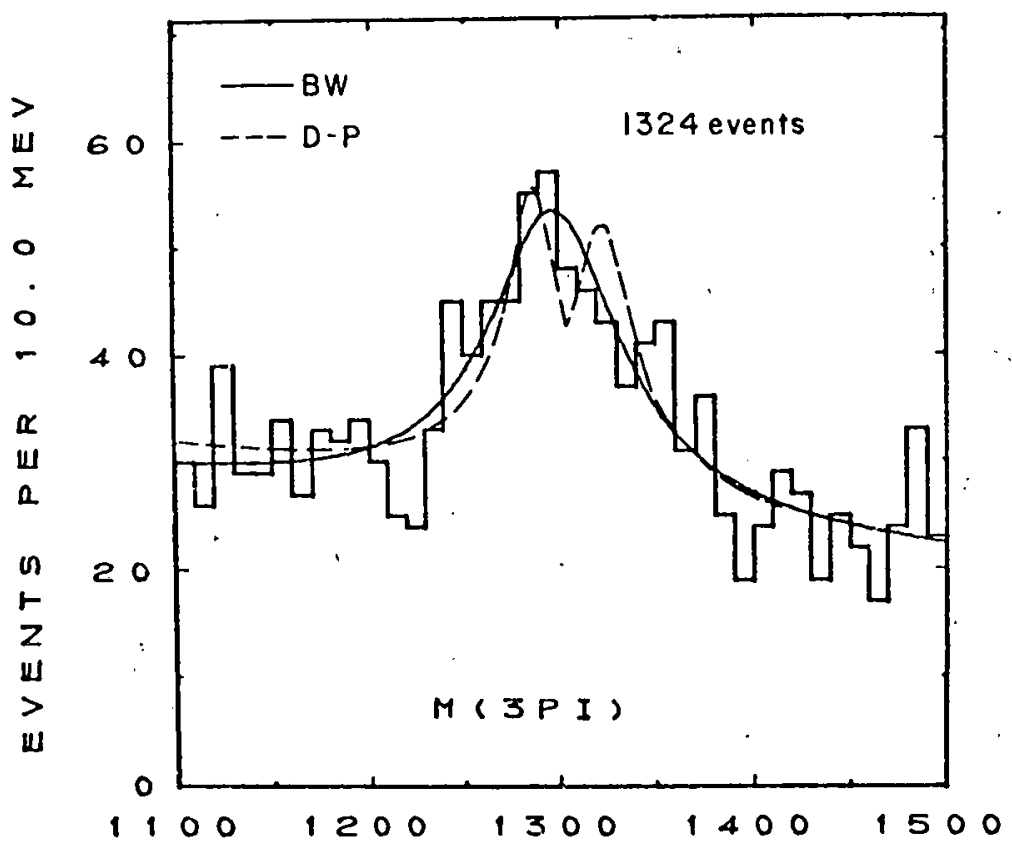

Fig. 11. The $3 \pi$ mass plot of the LRL experiment for momentum transfer cut as for the CERN experiment at the same energy $(0.20<-t<0.29) . \Delta^{t+}$ events have been removed.

are 770 events in the region 1200 to $1400 \mathrm{MeV}$ and no splitting is evident: However, the same is not sufficient to discriminate between the two hypotheses, the likelihood ratio of D-P over BW being $16 \%$.

Conclusions. The CERN CBS data at $2.6 \mathrm{GeV} / \mathrm{c}$ in Fig. $1 \mathrm{a}$ shows structure at the same place as the $7 \mathrm{GeV} / \mathrm{c}$ data, therefore the splitting does not seem to depend upon the incident momentum. The experiment, however, was done in about the same momentum transfer region as the MMS experiment, whereas the LRL experiment was done overall values of $t$, so it is possible that the splitting depends upon the value of $t$. If we accept the data of Fig. 11 as evidence against the double-pole an attractive possibility is $a$. dependence on the charge of the incident pion. This hypothesis would still explain why the two CERN experiments done at similar. values of $t$ but at different incident momentum show the same structure.

This last hypothesis is discussed further in Section 6. 
Comparison of $K^{ \pm} K_{1}^{\prime}$ data. Figure 12 includes the CERN and LRL data for the $K^{ \pm} K_{1}$ decay mode plotted in $7.5-\mathrm{MeV}$ bins. One question often asked is: are these histograms consistent with each other? In order not to wash out the differences we compare them in a restricted region, where the disagreement shows the most, that is the nine bins centered around $1300 \mathrm{MeV}$ from $\mathrm{M}$ $=1265 \mathrm{MeV}$ to $\mathrm{M}=1332.5 \mathrm{MeV}$. The formula used is ${ }^{19}$

$$
x^{2}=\sum_{i} \frac{\left(A_{i} R-B_{i}\right)^{2}}{A_{i} R+B_{i} R}
$$

where $A_{i}$ is the number of events in the ith bin of the LRL histogram, $B_{i}$ is the number of events in the corresponding bin of the CERN histogram, and $R$ is $\sum_{i} B_{1} / \sum_{i} A_{1}(R=100 / 68=1.47)$. The $x^{2}$ obtained is $x^{2}=17.7$ for nine degrees of freedom, which cor responds to a probability of less than $5 \%$.

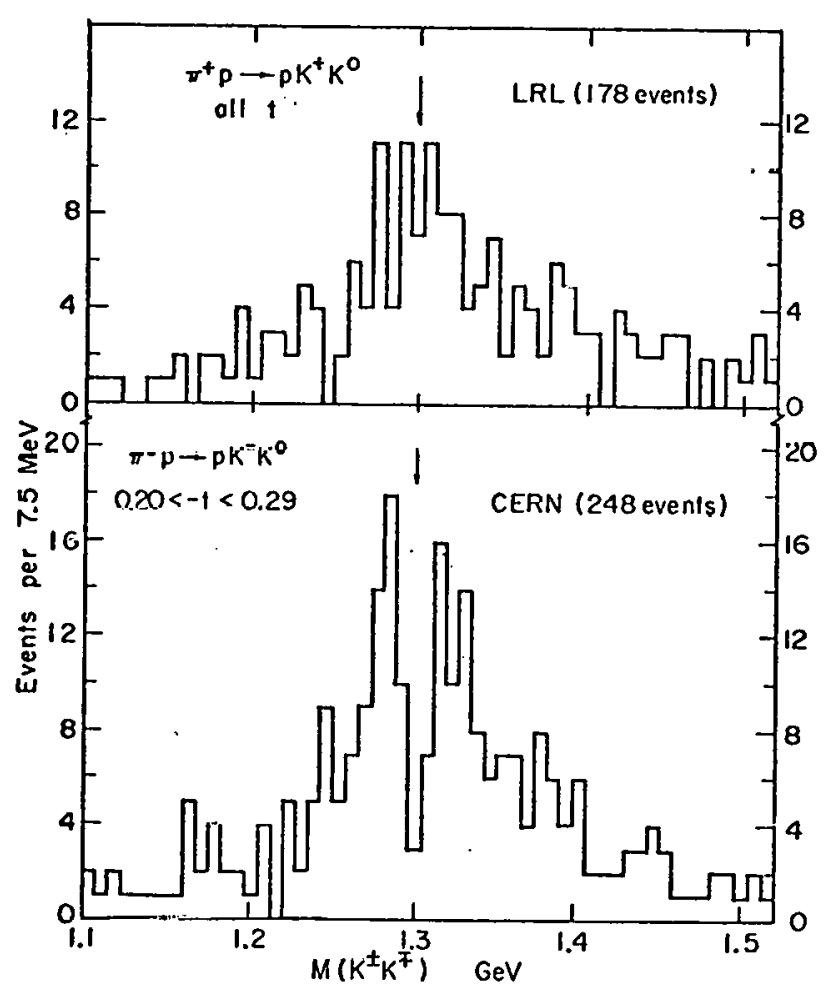

Fig. 12. Comparison of CERN and LRL data in the $K^{ \pm} K_{1}$ decay mode. (a.) LRL data $\left(\Gamma_{r} / 2-3.6 \mathrm{MeV}\right)$, (b) CERN data $\left(\Gamma_{\mathbf{r}} / 2=10 \mathrm{MeV}\right)$. 
The neutral $A_{2}$ has been so far studied in the reactions

$$
\begin{aligned}
& \pi^{-} \mathrm{p} \rightarrow \mathrm{n} \mathrm{K}_{1} \mathrm{~K}_{1}, \\
& \pi^{+} \mathrm{p} \rightarrow \Delta^{++} \mathrm{A}_{2}{ }^{0} .
\end{aligned}
$$

In both reactions the $f$ meson can be produced along with the $A_{2}$, and, since they have the same quantum numbers, interference effects may confuse the situation. However, in reaction (9) the decay mode $\mathrm{A}_{2} \rightarrow \pi^{+} \pi^{-} \pi^{-0}$ is free from $f$ interference.

Crennell et al. ${ }^{10}$ studied reaction (8) at $6 \mathrm{GeV} / \mathrm{c}$ and reported a very narrow peak $\left(\Gamma=20_{-}^{+16} \mathrm{MeV}\right)$ at a mass of $1311 \pm 5 \mathrm{MeV}$. It is not clear what is being seen here because the width is so narrow (for $\mathrm{f} \Gamma=150 \pm 25 \mathrm{MeV}$, for $\mathrm{A}_{2}{ }^{0} \Gamma=89 \pm 4$ MeV). ${ }^{13}$ The claim that this narrow peak corresponds to the $A_{2 \mathrm{H}}$ and that, because of it, the two halves of the $A_{2}$ have different $\mathrm{J}^{\mathrm{P}}$ assignments is now disproved by the CPL data, ${ }^{8}$ the CERN data, ${ }^{3}$ and the LRL data. ${ }^{4}$ 'I'his narrow peak still remains to be explained; it may be caused by some peculiar interference of $f$ and $A_{3}$, or just poor statistics (only 25 events in this peak). Bcush ct al. 20 on the other hand, studied the same reaction at 5,7 , and $12 \mathrm{GeV} / \mathrm{c}$ incident $\pi^{-}$with large statistics, and found a broad peak of $\approx 140 \mathrm{MeV}$ which they fit by adding incoherently $f$ and $A_{\text {? }}$.

These two experiments are clearly in contradiction, and do not shed much light on the $A_{2}$ meson.

Studies of reaction (9) have failed ${ }^{7}$ to show any splitting in $\mathrm{A}_{2}{ }^{0} \rightarrow \pi^{1} \pi^{-} \pi^{0}$, but the quoted resolution $\left(1_{\mathbf{r}}^{\prime} / 2=10 \mathrm{MeV}\right)$ is clearly worse than in the charged case. As for the decay into $\mathrm{K}^{+} \mathrm{K}^{-}$or $\mathrm{K}_{1} \mathrm{~K}_{1}$, the statistics available so far are insufficient for any conclusions. It should be mentioned here that the total width 
of the $A_{2}^{0}$ signal in this reaction is consistent with the width of the charged $A_{2} \cdot 7,13$

$\mathrm{V} \quad$ SPIN AND PARITY OF $\mathrm{A}_{2}$

Kruse has summarized at this Conference ${ }^{21}$ the results of the various spin analyses of the $A_{2}$ region. The data on the charged $A_{2}$ have been analyzed as a whole or in two parts and the $\mathrm{J}^{\mathrm{P}}=2^{+}$assignment is now established for the whole region. Both the CERN ${ }^{1}$ and LRL experiments ${ }^{22}$ have studied the $\mathrm{A}_{2} \rightarrow \rho \pi$ decay mode and have conclusive evidence for the $\mathrm{J}^{\mathrm{P}}=2^{+}$assignments for both halves.

The $\mathrm{K}^{+} \mathrm{K}_{1}$ and $\mathrm{n \pi}^{+}$data of the LRL group ${ }^{22}$ show very clearly that $\mathrm{J}^{\mathrm{P}}=2^{+}$is the most likely assignment, as does the $\eta \pi$ compilation that Kruse showed at this Conference. We therefore assume that if the $A_{2}$ is split, both states have $\mathrm{J}^{P}=2^{+}$.

VI CONCLUSIONS ON $A_{2}$ SPLITTING

From all the detailed discussion of the preceding sections, and assuming that none of the crucial experiments is wrong, my conclusions on the $A_{2}$ splitting can be summarized as follows:

1. Of the many experiments discussed only three have conclusive results. These are: (a) the CERN experiments, which consistently show a double-pole structure in $\mathrm{A}_{2}{ }^{-}$decaying into $\mathrm{K}^{-} \mathrm{K}^{0}, \mathrm{MM}^{-}$and $\eta \pi^{-}$(with poor statistics in the $\eta \pi^{-}$channe1). ${ }^{1}$ (b) The LRL experiment, 4 which consistently shows no structure in $\mathrm{A}_{2}{ }^{+}$, decaying into $\mathrm{p}^{0} \pi^{+}, \mathrm{K}^{+} \mathrm{K}_{1}$, and $\eta \pi^{+}$. (c) The pp experiment of the CPL collaboration, ${ }^{8}$ which shows splitting in $\mathrm{A}_{2}^{ \pm} \rightarrow \mathrm{K}^{ \pm} \mathrm{K}_{1}$. In addition there are many other bubble chamber experiments, which do not show any evidence either way. $7,10-13$

2. The data on the neutral $A_{2}$ do not help in understanding the situation. 
3. Spin analyses of $\mathrm{A}_{2}{ }^{ \pm}$into all three channels $\rho^{0} \pi^{ \pm}$, $\eta \pi^{ \pm}, \mathrm{K}^{+} \mathrm{K}_{1}$ definitely prefer the $\mathrm{J}^{\mathrm{P}}=2^{+}$assignment for the overall $\mathrm{A}_{2}$ enhancement and for the two halves.analyzed separately (for both $\rho^{0} \pi^{+}$and $\rho^{0} \pi^{-}$decays). $1,21,22$

4. The LRL experiment'indicates that the two-parameter double-pole formula of Eq. (5) does not fit the data. A more gencral double-pole formalism, as discussed by Rebbi and 'Slansky, ${ }^{15}$ should therefore be adopted. This corresponds to fitting the data with two coherently produced resonances, as already done by the CERN group. 2

5. Comparison of the CERN and LRL experiments, which both use pion beams, shows that at the present time the splitting of the $A_{2}$ peak does not seem to depend on the incident beam momentum whereas it may depend on the momentum transfer. A dependence on charge of the incident beam alone, however, could probably explain the effect.

A model that has been very popular in the corridors at this Conference and that will be discussed in Sutherland's review talk originates from the analogy with the $\rho-\omega$ interference model of Goldhaber et al. ${ }^{23}$ In this model two $2^{+}$mesons would be produced, one mostly coupled to $\rho$ exchange, the other mostly coupled to $f$ exchange. Since $\rho$ and $f$ have different isotopic spin, the two amplitudes would add in the $\pi^{+}$case and subtract in the $\pi^{-}$ case. Of course, the detailed prediction of this model should be worked out and checked with the experiments.

Another model, suggested by Arnold and Uretsky, 24 considers the possibility that one of the $A_{2}$ 's is an exotic resonance, that is, an isospin $\angle$ state. The two states would mix by virtue of electromagnetic interactions.

In conclusion, it scems to me that the double-pole struc ture of Eq. (5) should be abandoned and that models which predict two interfering resonances are more likely to explain all the data. To check the possible models, however, may require a lot more experiments at different incident momenta, different momentum 
transfers, and different incident beams--that is, a lot more time and effort on the part of the experimental physicists.

VIII $\mathrm{K}^{*}(1420)$ AND $\mathrm{f}(1270)$. ANY STRUCTURE?

If the $\mathrm{A}_{2}$ is really two states, one would expect that the other members of the nonet also show some structure. The LRL group has investigated $K^{*}(1420)$ and $f(1270)$. No double-pole structure such as Eq. (5) has been detected so far in either of these two states.

A. $K^{*}(1420)$. Davis et al. ${ }^{5}$ have investigated the reaction

$$
\mathrm{K}^{+} \mathrm{p} \rightarrow \mathrm{K}^{+} \pi^{-} \pi^{+} \mathrm{p} \text { at } 12 \mathrm{GeV} / \mathrm{c}
$$

All together 27000 events of this type have been analyzed, of which 5665 events fall in the mass interval 1200 to $1640 \mathrm{MeV}$. The resolution is $6.5 \mathrm{MeV}$. Figure 13 shows all the data for the above reaction and the $K^{*}(1420)$ region alone. The $B W$ fit is very good, whereas the two-parameter D-P of Eq. (5) has a confidence level of $<1 \%$. These results are summarized in Table $\mathrm{V}$.

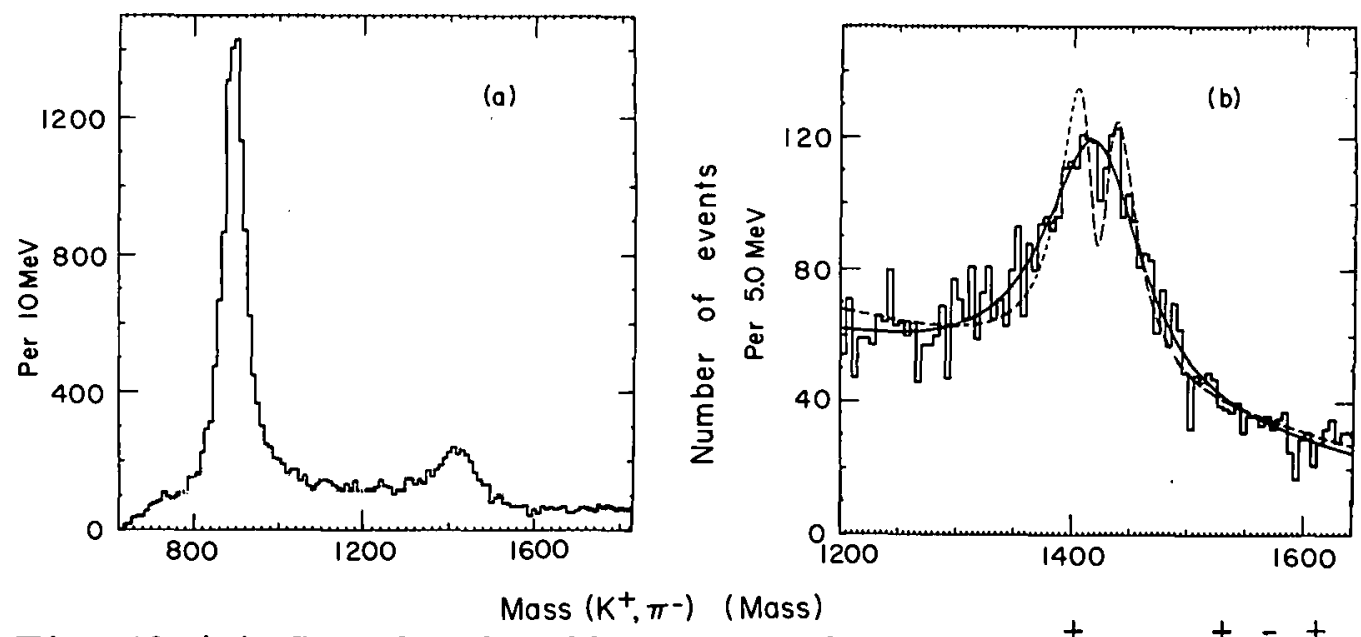

Fig. 13. (a) Sample of 27000 events of the type $\mathrm{K}^{+} \mathrm{p} \rightarrow \mathrm{K}^{+} \pi^{-} \pi^{+} \mathrm{p}$ at $12 \mathrm{GeV} / \mathrm{c}$ studied by Davis et al. (Ref. 5) (b) The $\mathrm{K}^{*}(1420)$ region: - BW fit $(47 \%), \ldots \mathrm{D}-\mathrm{P}$ fit $K 1 \%$. 
Table V. Fits to the $K^{*}(1420)$ and $f(1270)$ events.

\begin{tabular}{lccccccc} 
& $\begin{array}{l}\text { Total } \\
\text { events }\end{array}$ & $\begin{array}{l}\text { Events in } \\
\text { resonance }\end{array}$ & $\Gamma_{\mathrm{r}} / 2$ & $\mathrm{M}$ & $\Gamma$ & $\mathrm{BW}$ & $\mathrm{D}-\mathrm{P}$ \\
\hline $\begin{array}{l}\mathrm{K}(1420), \\
1320-1520\end{array}$ & 5665 & 2200 & 6.5 & $1421 \pm 3$ & $101 \pm 10$ & $47 \%<1 \%$ \\
$\begin{array}{l}\mathrm{f}(1270), \\
1000-1600\end{array}$ & 9307 & 4150 & 8.3 & $1472 \pm 5$ & $180 \pm 15$ & $71 \%<0.01 \%$ \\
\hline
\end{tabular}

B. $f(1270)$. The LRL group 22 has investigated $f$ production in the reaction

$$
\pi^{+} \mathrm{p} \rightarrow \Delta^{++} \pi^{+} \pi^{-}(30740 \text { events })
$$

at $7 \mathrm{GeV} / \mathrm{c}$ incident momentum (see Fig. 14). In the region 1000 to $1600 \mathrm{MeV}$ there are 9307 events which have been fitted to the $\mathrm{BW}$ and to the D-P formula of Eq. (5). Here the resolution is $\Gamma_{\mathrm{r}} / 2=8.3 \mathrm{MeV}$.

Again a D-P formula such as Eq. (5) fits very badly.

None of these two stales has been filled will a lwuinterfering resonance hypothesis. It is probably not difficult here to find parameters for the two resonances and a phase such

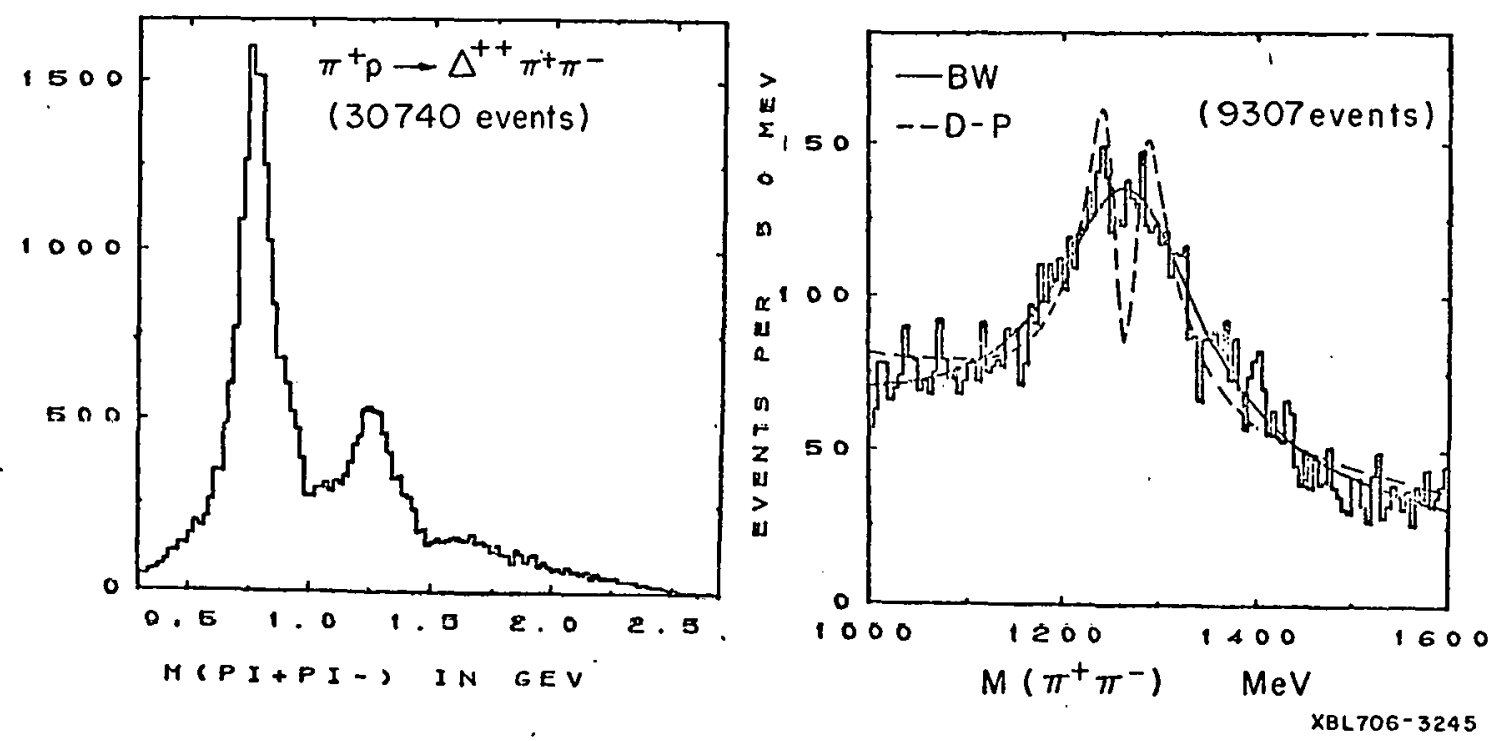

Fig. 14. (a) The 30740 events of the reaction $\pi^{+} \mathrm{p} \rightarrow \Delta^{++} \pi^{+} \pi^{-}$ $7 \mathrm{GeV} / \mathrm{c}$ (LRL data). (b) Fits to the f region: $-\mathrm{BW}$ $(71 \%),--D-P(<0.01 \%)$. 
that a good fit is obtained. Here again the conclusion is that the two-parameter formula of Eq. (5) does not fit the data.

\section{ACKNOW LEDGMENTS}

I wish to thank my co-workers in the LRL experiment (Ref. 4) for the effort they put into getting the data ready for this Conference. Work done under the auspices of the U.S. Atomic Energy Commission.

\section{REFERENCES}

1. The CERN Boston Spectrometer Group, Decay Analysis of $A_{2} L$ and $\mathrm{A}_{2}{ }^{\mathrm{H}}$ in the channels $\mathrm{A}_{2}{ }^{-} \rightarrow \mathrm{K}_{1}{ }^{0} \mathrm{~K}^{-}, \mathrm{A}_{2}{ }^{-} \rightarrow \rho^{0} \pi^{-}$, $A_{2}{ }^{-} \rightarrow \eta \pi^{-}$, presented at this Conference by M. Martin.

2. H. Benz et al., Phys. Letters 28B, 233 (1968), includes data from the MMS and the CBS.

3. R. Baud et al., Phys. Letters 31B, 397 (1970).

4. A. Barbaro-Galtieri, S. E. Derenzo, S. M. Flatté, J. H. Friedman, M. A. Garnjost, G. R. Lynch, M. S. Rabin, F. T. Solmitz, F. Buhl, L. Epperson, S. Protopopescu, R. Ott, Production of $\mathrm{A}_{2}$ Mesons at $7 \mathrm{GeV} / \mathrm{c}$, to be published.

5. P. J. Davis, S. E. Derenzo, S. M. Flatté, M. A. Garnjost, . G. R. Lynch, and F. T. Solmitz, Phys. Rev. Letters $\underline{23}$, 1071 (1969).

6. Lawrence Radiation Laboratory, Group A, same authors as Ref. 4, Spin-Parity Analysis of $\mathrm{A}_{2}$ Mesons, to be published.

7. K. Böckman et al., Bonn-Durham-Nijmegen-Paris (E.P.) Torino Collaboration, Nucl. Phys. B16, 221 (1970).

8. M. Aguilar-Benitez et al., CERN-Paris (C. D. F.)-Liverpool Collaboration, Phys. Letters 29B, 62 (1969).

9. Maglic's source of this erroneous information is probably his own review talk in Proceedings of the Lund International Conference on Elementary Particles, Lund, Sweden, June 1969 (Berlinska Boktrycheriet, Lund, Sweden, 
1969) p. 269. There, the references are somewhat confused in fact he counts the experiments of the CERN group three times, twice as bubble chamber experiments. The other experiment he includes is our Ref. 10 below.

10. D. J. Crennell, U. Karshow, K. W. Lai, J. M. Scarr, and I. O. Skillicorn, Phys. Rev. Letters 20, 1318 (1968). The two-peak fit for this experiment is better, but not significantly, than the one-peak fit.

11. D. H. Coyne, G. S. Abrams, W. R. Butler, G. Goldhaber, B. H. Hall, J. MacNaughton, and G. H. Trilling, Bull. A.m. Phys. Soc. 15, 658 (1970), and private communication. This is $\approx 20$ events/ $\mu$ b exposure, and no conclusions on the $\mathrm{A}_{2}$ splitting can be drawn.

12. U: Kruse, University of Illinois, private communication at this Conference. They have two exposures at 5 and $7 \mathrm{GeV} / \mathrm{c}$ incident $\pi^{-}$corresponding to $\approx 15$ events $/ \mu b$. No conclusion can be drawn on the $A_{2}$ splitting.

13. For more information on this point see listings of Review of Particle Properties by the Particle Data Group, Rev. Mod. Phys. 42, 87 (1970).

14. M. L. Goldberger and K. M. Watson, Phys. Rev. 136B, 1472 (1964); K. E. Lassila and V. Ruuskanen, Phys. Rev. Letters 17, 49 (1966) and Phys. Rev. Letters 19 762 (1967); and many others.

15. C. Rebbi and R. Slansky, Phys. Rev. 185, 1838 (1969), and Doubled Resonances in the Eigenchannel Representation, CalTech Report 68-227 (1970).

16. W. Kienzle, in Meson Spectroscopy, edited by C. Baltay and A. H. Rosenfeld (W. A. Benjamin, Inc., New York, 1968), P. 256.

17. This point has been widely discussed; see, for example, A. H. Rosenfeld et al. , Rev. Mod. Phys. 40, 77 (1968); S. -Y. Fung et al., Phys. Rev. Letters 21, 47 (1968), and A. Barbaro-Galtieri and P. Söding, in Meson Spectroscopy, 
edited by C. Baltay and A. H. Rosenfeld (W. A. Benjamin, Inc., New York, 1968), p. 137.

18. D. J. Crennell, U. Karshon, K. W. Lai, J. S. O'Neall, and J. M. Scarr, Phys. Rev. Letters 22, 1327 (1969).

19. See, for instance, H. Cramér, Mathematical Methods of Statistics (Princeton University, Princeton, N. J., 1946), p. 448, formula (30.6.2).

20. W. Beusch et al, , Zurich-CERN Collaboration, Phys. Letters 25B, 357 (1967).

21. U. Kruse, Review of Spin and Parity Analysis in the $A_{2}$ Region, paper presented at this Conference.

22. Lawrence Radiation Laboratory Group A, same authors as Ref. 4, Study of $\mathrm{f}$ Mesons at $7 \mathrm{GeV} / \mathrm{c}$, to be published.

23. A. S. Goldhaber, G. C. Fox, and C. Quigg, Phys. Letters 30B, 249, (1969).

24. R. C. Arnold and J. L. Uretsky, Phys. Rev. Letters, 23, 444, (1969). 


\section{LEGAL NOTICE}

This report was prepared as an account of Government sponsored work. Neither the United States, nor the Commission, nor any person acting on behalf of the Commission:

A. Makes any warranty or representation, expressed or implied, with respect to the accuracy, completeness, or usefulness of the information contained in this report, or that the use of any information, apparatus, method, or process disclosed in this report may not infringe privately owned rights; or

B. Assumes any liabilities with respect to the use of, or for damages resulting from the use of any information, apparatus, method, or process disclosed in this report.

As used in the above, "person acting on behalf of the Commission" includes any employee or contractor of the Commission, or employee of such contractor, to the extent that such employee or contractor of the Commission, or employee of such contractor prepares, disseminates, or provides access to, any information pursuant to his employment or contract with the Commission, or his employment with such contractor. 
TECHNICAL INFORMATION DIVISION LAWRENCE RADIATION LABORATORY

UNIVERSITY OF CALIFORNIA

BERKELEY, CALIFORNIA 94720 